\title{
Simone Greco, Diccit. Diccionario combinatorio español-italiano. A-K.
}

\author{
Presentación de Manuel Carrera Díaz \\ Ogliastro Cilento: Licosia, 2019, 373 pp
}

La lexicografía bilingüe español-italiano, como se dice en la obra, no ha sido demasiado prolífica y sus productos han ido surgiendo "con extraordinaria parsimonia" (p. 8). En efecto, tras un periodo en el que se atemperó dicha parsimonia (entre 1995 y 2012), bien pocas han sido las obras dignas de mención. Por ello constituye una excelente noticia la publicación del Diccit, fruto de un proyecto de investigación dirigido por Simone Greco, profesor de español de la Universidad de Bari, que pretende "registrar todas las entradas del vocabulario español” (p. 18). Esta obra, además, viene a cubrir — si bien es cierto que por ahora parcialmente- una laguna de la lexicografía italoespañola, la de los diccionarios combinatorios. En realidad, la aparición del Diccit supone un importante hito, puesto que viene a colocarse junto al único diccionario de combinaciones léxicas del español publicado hasta ahora, el dirigido por Ignacio Bosque. Ello contrasta con una mayor abundancia para el italiano, donde contamos con los de Urzi, de Tiberi y de Lo Cascio.

Más allá del mérito de su novedad, es sin duda relevante su intención didáctica, puesto que resulta un útil instrumento para los estudiantes italohablantes de español y a los hispanohablantes de italiano en un sector al que otros diccionarios (bilingües o monolingües) y los manuales para la enseñanza del idioma no suelen prestar la debida atención, a pesar de que el de las combinaciones léxicas más o menos fijas (en especial las colocaciones) suponen una de las mayores dificultades en todas las etapas del aprendizaje de una lengua extranjera.

A pesar de la pretensión de completitud manifestada en la p. 18, el propio autor se apresura a limitar su alcance: "Diccit es un diccionario bilingüe español-italiano de colocaciones - la unión preferente de dos lexemas- del grupo SUSTANTIVO + VERBO" (p. 10). Esta limitación se justifica por una necesidad operativa de limitarse a lo más urgente (p. 10).

Todo lo antedicho nos permite caracterizar de manera precisa esta obra: es un diccionario bilingüe de carácter unidireccional (español $\rightarrow$ italiano), con una nomenclatura limitada a una categoría gramatical (sustantivos y locuciones sustantivas) y en cuya microestructura se ofrecen en exclusiva los verbos con los 
cuales se combina habitualmente el sustantivo-lema, además de informaciones de tipo sintagmático (regencias).

Otra limitación, recogida en el título, es la del lemario, que comprende solo sustantivos comprendidos entre las letras A y K, algo ciertamente inusitado que esperemos sea subsanado a la mayor brevedad posible.

La introducción presenta un carácter híbrido, puesto que comprende una parte justificativa, que interesa sobre todo a los especialistas (epígrafes 1-5 y quizá 6) y otra con las instrucciones de uso propiamente dichas (epíg. 7). Habría sido preferible, en aras de la claridad y para no confundir al usuario real de este diccionario, dividir la introducción en dos: una Introducción (que el usuario podría ignorar) y unas Instrucciones de uso (que aquel debería consultar para sacar el necesario provecho de la obra).

La microestructura reviste una cierta complejidad y no siempre resulta transparente para un usuario no demasiado avezado. Las entradas están organizadas en dos columnas, la de la izquierda para el español y la de la derecha para el italiano. Cada artículo está encabezado por un sustantivo (o una locución sustantiva, lo que supone una importante novedad en la lexicografía bilingüe, que normalmente recoge solo entradas monorremáticas) del español, al que siguen en orden alfabético aquellos verbos con los que se combina habitualmente. Se distingue entre aquellos verbos que tienen al sustantivo en cuestión como sujeto (en letra redonda) y aquellos en los que es objeto directo (en negrita). También se tiene en cuenta la doble construcción (pronominal/no pronominal) de muchos verbos, poniendo en negrita la terminación (-se/-si) o bien el radical verbal. Para aquellos verbos que rigen un complemento preposicional se indica entre llaves la preposición correspondiente (por ejemplo: $\mathrm{Crema}^{2} \diamond \operatorname{rellenar}\{$ con $\}$ ); se ofrecen asimismo indicaciones sobre "ejemplos de posibles realizaciones cotextuales o colocaciones concatenadas" (p. 11), lo que Manuel Seco llama contorno, como en: Delantero $\diamond$ disparar (el balón), marcar (goles). Si tales elementos son opcionales aparecerán entre corchetes, como aquí: Embriaguez $\diamond$ presentar [síntomas de].

En la segunda columna, y sobre un fondo azul un tanto chillón, se halla la información sobre el equivalente italiano, con las mismas pautas descritas para el español. En la mayoría de entradas se da una equivalencia unívoca hacia un solo equivalente, con algunas excepciones (como en: Calle $<>$ Via / Strada, p. 16). En ciertos casos de polisemia del lema español se ha divido acertadamente el artículo en más de una entrada, atendiendo al hecho de que cada una de ellas tiene un equivalente diferente (véase este elocuente ejemplo: Hoja ${ }^{1}<>$ Foglia; Hoja ${ }^{2}<>$ Foglio; $\mathrm{Hoja}^{3}<>$ Lama).

Nos encontramos, pues, ante una obra muy útil, que cubre un vacío existente en la lexicografía hispano-italiana, puesto que muchos diccionarios monolingües y la mayoría de los bilingües no prestan la debida atención a tan importante aspecto, básico para el aprendiz de una lengua extranjera.

Hay que señalar ciertas deficiencias que podrían subsanarse sin demasiada dificultad. La más importante es probablemente la excesiva esquematicidad de las indicaciones contextuales o sintácticas, que difícilmente orientarán de 
manera cumplida al usuario. Por ejemplo, sería imprescindible que, además de la preposición que rige el sustantivo, se indicara la necesidad o no de utilizar el artículo (determinado o indeterminado), algo que resulta asimismo esencial en casos como estos:

Carta $(s) 3 \diamond$ jugarse, jugarse (algo) $\{a\}$

Encontronazo $\diamond$ darse, provocar, sufrir, tener (con alguien)

En el primero se debería indicar la necesidad del artículo las (o una), y en el segundo que no se puede prescindir del indeterminado un. Es muy probable que lo escueto de las informaciones sintagmáticas ofrecidas responda al soporte en papel del diccionario, que ha limitado tradicionalmente la información disponible y el modo de ofrecerla, mediante convenciones tipográficas cada vez más sofisticadas y un potente aparato de abreviaturas y signos. Estas limitaciones ya no tienen razón de ser en la era de los diccionarios electrónicos (en sus múltiples formatos, aunque sobre todo en los diccionarios en línea), donde puede obviarse la restricción de espacio y ofrecer la información requerida de una manera más flexible y ajustada a las necesidades de cada usuario. Sería deseable que en un futuro no lejano este diccionario pudiera dar el salto a internet, sin duda su ámbito natural de difusión.

Debería, por último, corregirse alguna expresión errónea o algún calco del italiano (como reiterante [por reiterada], p.10; o Entrada con más acepciones [por Entrada con varias acepciones], p. 19), además de la errónea separación de sílabas al final de línea, que sigue las normas de la lengua italiana y no las de la española. 
